\title{
From planning to motivations: citizen science comes to life
}

\section{Emma Weitkamp}

Abstract

Keywords

Rationales
This issue forms Part II of JCOM's collection of articles and essays exploring the field of citizen science. Here I introduce the articles in Part II, outlining how they contribute to our understanding of the ways that volunteers participate in citizen science projects, what motivates this participation and what learning arises as a result of participation.

Citizen science; Participation and science governance

This time last year I was busy writing a chapter on crowd-sourced research for my new book, Creative Research Communications [Wilkinson and Weitkamp, 2016] and eagerly awaiting submissions for this Special Issue on Citizen Science. Writing the chapter highlighted huge gaps in our knowledge of citizen science: for example, relatively little is known about why people participate in these projects (a topic addressed by several articles in this Special Issue) or the types of engagement they expect, though several authors have proposed classifications of the citizens involvement on a ladder from the most passive to the most active (co-production) (references below). This idea of analysing activities on a ladder of increasing levels of participation is in fact now used in many other cultural and social spheres, from art to policy making, and testifies a general trend of contemporary societies to blur the boundaries between performers and audiences, experts and lay people, etc. [see for example, Brown and Novak-Leonard, 2011; Bonney et al., 2009; Involve Foundation, 2015; Socientize, 2014]. Regarding citizen science, Bonney et al. [2009] outline for example three types of citizen science projects - contributory, collaborative and co-created projects - each offering different levels of public involvement from simply collecting and contributing data to projects where the public has a role throughout the scientific process from the questions asked through to dissemination of findings.

The papers in this collection build on these issues, exploring different rationales for citizen science programmes, volunteer motivations and learning.

As Bonney et al. [2009] highlight, there are different styles of citizen science projects and these serve different needs. Buckland-Nicks, Castleden and Conrad [2016] pick up on this topic in the context of community based water monitoring programmes in Canada, highlighting two primary drivers for such projects: those designed to contribute to government decisions and environmental management and those designed to encourage community awareness and engagement as well as 
environmental stewardship. This led Buckland-Nicks et al. to conceive of three types of water monitoring programmes:

- those led by government with a view to collect high quality data for the purposes of decision making and management. These programmes may involve volunteers, but the emphasis on collecting high quality data may make them more suited to staff data collection and may make it more challenging to keep volunteers motivated.

- integrated programmes that seek to generate high quality data while at the same time secure community engagement and support environmental stewardship. These programmes may be instigated by a variety of parties, from government through to NGOs and community groups. Focus is on quality data but with some flexibility in design and implementation.

- basic programmes which are designed primarily to encourage volunteer engagement. These programmes have educational goals and are less concerned about the rigour of the data collected.

While the authors highlight that all three approaches can create public awareness, provide useful watershed data and identify environmental hotspots, they also argue for the importance of planning and aligning the project goals with the approach taken and that these need to be aligned to the resources available. Converse et al. [2016] also highlight the importance of planning when developing a citizen science programme, but particularly highlight that ecological monitoring progammes need to be of sufficient length to enable ecological trends to be measured, ensure that relevant data are collected (particularly if some agencies or groups do not collect yearly data) and allow time for the programme to gain visibility. The Bosque Environmental Management Programme is a partnership between a university and school that seeks to provide 'science, education, and stewardship of the Rio Grande and its watershed through long-term, hands-on student research of ecosystem response and function to inform policy' [BEMP, 2015], so its mission is both educational and to inform environmental management of the watershed. As such, this programme needs to secure ongoing support (including financial) from these local agencies over a long period of time, and the article explores strategies to facilitate this long term engagement and support.

There is much discussion in the literature about the potential of citizen science projects (particularly those that move beyond citizens as data gatherers or processors) to enable more democratic participation in science. Del Savio, Prainsack and Buyx [2016] argue that even projects that involve citizens only in the supply of samples and funding of research can enable and encourage participation. Focusing on three projects that explore the human microbiome, the American Gut Project, the British Gut Project (both run by academic researchers) and uBiome (a commercial venture), Del Savio, Painswick and Buyx argue that the lack of traditional funding route gave 'citizens limited but not negligible direct power on agenda setting and promoting the democratic aspirations underpinning citizen engagement initiatives'. They also argue that this type of project can catalyse discussions between researchers (who need the funding and samples that are provided by volunteers) and citizens at least in part because crowdfunding is imbued with a democratic ideology (even if this is not the driving rationale of the scientists). 
Bethany Alender [2016] finds similarities between citizens engaged in water quality and those more generally involved in environmental volunteerism. She suggests that in the case of environmental monitoring, participants may be motivated by a desire to contribute to environmental stewardship. Thus, for her survey respondents, the three strongest motivators - 'helping the environment', 'contributing to the local community' and 'connecting with nature' - are also shared more generally by those involved in environmental volunteering. She also points out that volunteers felt strongly that the data they collect should be made publicly available and highlighting the intersection between citizen science and open science (and the need to consider how data might be made 'open' at the outset of a citizen science project) and that volunteers want to know that the data they have collected has had an impact (e.g. on policy or management), also highlighting the need for citizen science projects to build in opportunities to communicate with volunteers.

In the online sphere, Jennett et al. [2016] explored the relationships between motivation to participate, learning and creativity to develop what they call the MLC model for citizen science. This model considers motivations (which amongst their interviewees was primarily an interest in contributing to scientific research) as the driver for becoming engaged with a project and then explores how participation influences learning and identity as a volunteer. They suggest that the community that exists around projects is crucial to enabling volunteers to participate in and learn through online citizen science projects (e.g. through supporting individuals to gain relevant knowledge). This community also facilitates the development of volunteer's identities as they are then able to support new volunteers and begin to see themselves as part of a community. Creativity sits alongside this in projects that facilitate community involvement (e.g. through suggesting improvements). This study highlights the importance of the social and community aspects of citizen science projects in online environments, offering insights into both the design and evaluation of citizen science projects.

While the primary purposes of many citizen science projects are to enable citizens to participate in scientific research and to collect useful scientific data, there has been an underlying assumption that through participation volunteers will also learn something about science and possibly also about the scientific process. Roger and Klistorner [2016] point out that it is not just the volunteers who learn, but also the scientists. Examining a BioBlitz in Australia, Roger and Klistorner [2016] focused on the potential of face to face citizen science as a means of opening dialogue and stimulating two way engagement, something that was valued by both the scientists and lay people participating in the event. The opportunities afforded by engaging the local community in an event that opened a dialogue are discussed in the paper.

Online citizen science projects have attracted considerable interest in recent years and Masters et al. [2016] present evidence that participants also learn through participation in online citizen science projects. They suggest that regular participation in online citizen science projects leads to an increase in subject specific knowledge (but not general scientific literacy). They also suggest that communication (e.g. through blogs, Twitter and in project Talk) contribute to this 
learning by comparing Zooniverse projects that achieve high levels of communication with those that do not.

This collection of articles offers insights into a range of different types of citizen science projects and how they might facilitate citizen engagement and learning. The collection points to a strong interest in citizen science from the environmental research community ( 4 of the 7 have environmental themes) but also the diversity of science being investigated with the help of lay participants (from the human gut to the solar system). It raises questions about what constitutes citizen science as well as the ways in which citizens can participate, the reasons they participate and the benefits they gain. Seen in conjunction with Part I of the special issue (http:/ /jcom.sissa.it/archive/15/01) published in January 2016, it is clear that science communication scholars are grappling with a range of issues and questions about this old but developing form of citizen participation in science.

Alender, B. (2016). 'Understanding Volunteer Motivations to Participate in Citizen Science Projects: A Deeper Look at Water Quality Monitoring'. JCOM 15 (03), A04.

Bonney, R., Ballard, H., Jordan, R., McCallie, E., Phillips, T., Shirk, J. and Wilderman, C. C. (2009). Public Participation in Scientific Research: Defining the Field and Assessing Its Potential for Informal Science Education. A CAISE Inquiry Group Report. Washington, DC, U.S.A.: Center for Advancement of Informal Science Education (CAISE). URL:

http://www.informalscience.org/public-participation-scientific-resea rch-defining-field-and-assessing-its-potential-informal-science.

Bosque Ecosystem Monitoring Program (2015). BEMP Overview. URL: http: //www . bosqueschool .org/BEMP. aspx (visited on 21st March 2016).

Brown, A. S. and Novak-Leonard, J. L. (2011). Getting In On the Act. How arts groups are creating opportunities for active participation. The James Irvine Foundation. URL: https://www . irvine .org/arts/what-were-learning/getting-in-on-th e-act.

Buckland-Nicks, A., Castleden, H. and Conrad, C. (2016). 'Aligning Community-Based Water Monitoring Program Designs with Goals for Enhanced Environmental Management'. JCOM 15 (03), A01.

Converse, R., Shaw, D., Eichhorst, K. and Leinhart, M. (2016). 'Bringing Citizen Monitoring into Land Management: A Case Study'. JCOM 15 (03), A02.

Del Savio, L., Prainsack, B. and Buyx, A. (2016). 'Crowdsourcing the Human Gut. Is crowdsourcing also 'citizen science'?' JCOM 15 (03), A03.

Jennett, C., Kloetzer, L., Schneider, D., Iacovides, I., Cox, A. L., Gold, M., Fuchs, B., Eveleigh, A., Mathieu, K., Ajani, Z. and Talsi, Y. (2016). 'Motivations, Learning and Creativity in Online Citizen Science'. JCOM 15 (03), A05.

Masters, K., Oh, E. Y., Cox, J., Simmons, B., Lintott, C., Graham, G., Greenhill, A. and Holmes, K. (2016). 'Science Learning via Participation in Online Citizen Science'. JCOM 15 (03), A07.

Roger, E. and Klistorner, S. (2016). ‘BioBlitzes help science communicators engage local communities in environmental research'. JCOM 15 (03), A06.

Socientize (2014). White Paper on Citizen Science for Europe. European Commission. URL: http://www. socientize.eu/?q=eu/content/white-paper-citizen-science. 
The Engage2020 Consortium (2015). Engage 2020, Science, Society and Engagement. An e-Antology. The Involve Foundation. URL:

http://engage2020.eu/publications-page/.

Wilkinson, C. and Weitkamp, E. (2016). Creative Research Communication.

Manchester, U.K.: Manchester University Press.

Author

Dr. EmmaWeitkamp is an Associate Professor in Science Communication at the University of theWest of England, Bristol where she teaches on an MSc in Science Communication and provides training in science communication for practitioners and Ph.D. students. Emma is also Editor in Chief of JCOM.

E-mail: Emma.Weitkamp@uwe.ac.uk.

How to cite

Weitkamp, E. (2016). 'From planning to motivations: citizen science comes to life'. JCOM 15 (03), E. 